\title{
Learned Helplessness: A Case Study of a Middle School Student
}

\author{
Mary D. Walling \\ University of Memphis
}

\author{
Thomas J. Martinek \\ University of North Carolina at Greensboro
}

“I just give up. I can't play this game." Most children who participate in a wide variety of sport activities have no doubt become frustrated with their performance at times. Certainly, all youngsters have experienced failure in physical activities. Repeated failure experiences often have an impact on the formation of children's perceptions of ability. For most individuals, low self-perceptions of ability are specific to a particular sport or task; further, these perceptions are malleable and susceptible to change when people judge that they are increasing their level of mastery. For others, however, feelings of incapability can become a static condition in which individuals acquire a feeling of helplessness in attempting various tasks (Dweck, 1975; Elliot \& Dweck, 1988; Nicholls, 1984; Seligman, 1990; Thomas, 1989). According to Seligman and Maier (1967), the phenomenon of learned helplessness occurs when individuals perceive no relationship between their responses in a given situation and the resulting outcome. In other words, learned helpless individuals perceive little control over achievement outcomes during the performance of physical or academic tasks.

One of the main causes of learned helplessness is repeated failure in numerous achievement situations. For many children, the school setting has been a prime "breeding ground" for failure experiences (Dweck, 1986; Dweck \& Goetz, 1978; Stipek \& Gralinski, 1991). When children continually experience failure, they come to believe that nothing they do can change future outcomes. That is, they attribute failure to their lack of ability, an invariant and stable cause of achievement outcomes (Stipek, 1993; Stipek \& Gralinski, 1991). For adolescent students, it seems that learned helplessness would be especially compounded given that they have already had ample opportunities to succeed and fail (Reynolds \& Miller, 1989). The study of learned helpless adolescents, therefore, would appear to be appropriate.

The effects of learned helplessness have been found in the classroom setting. In many instances, the symptoms of learned helplessness are evident by students who show little if any persistence in learning tasks, especially difficult tasks. Unfortunately, teachers find it difficult to understand why some students with equal ability give up easily, whereas other students tenaciously persist (Dweck, 1975; Kozol, 1991; Martinek \& Griffith, 1994a, 1994b; Stipek, 1993).

Recently, several studies in physical education and sport have attempted to clarify the linkage between learned helplessness and poor performance (Martinek \& Griffith, 1993, 1994a, 1994b; Miserandino \& Hoffman, 1990; Prapavessis \& Carron, 1988). By examining the causes attributed to performance outcomes, the clarity of why learned helpless students do not persist has been greatly enhanced (Fincham, Hokoda, \& Sanders, 1989; Meyer \& Dicht, 1981). A primary focus of this work has been on how much control children perceive 
themselves to have over their achievement outcomes. The majority of these studies have compared learned helpless students to those that are mastery oriented.

Mastery-oriented students have been found to differ from their learned helpless counterparts in two ways. First, mastery-oriented youngsters possess a strong sense of personal control over performance outcomes. Having this attribute significantly increases their attempts to master a given task. Second, mastery-oriented students have also been able to develop a repertoire of problem-solving strategies to overcome the challenges of more difficult learning tasks. According to Dweck (1975) and Stipek (1993) this ability is in stark contrast to leamed helpless students who quickly give up when challenged; learned helpless students feel they have little chance of changing the course to failure.

An ultimate goal for researchers who have studied the leamed helpless phenomenon is to develop effective intervention techniques that will help alleviate this debilitating condition. Most strategies have focused on getting children to feel that they can change outcomes by trying hard (Dweck, 1975; Martinek \& Griffith, 1993; Seligman; 1990). This is done by encouraging leamed helpless students to attribute failure to a lack of effort rather than to a lack of ability. In this way learned helpless students learn to deal with failure in an affirmative way.

Unfortunately, there has been considerable variability in the success of these techniques. For some children, the intervention seems to work well, but for others there is little or no effect. We contend that the extent of the learned helpless condition is an important factor when considering remedial action. In other words, some children appear learned helpless only in particular situations, but for other children the condition pervades multiple aspects of their lives. We also believe that it is important to understand the underlying factors (e.g., home, school, peers) that have significant impact on a child's perceptions of ability and control. According to Seligman (1990) and Martinek and Griffith (1994b), knowing the pervasiveness and the causes of learned helplessness in a student will place the researcher in a better position to develop effective strategies for abating the condition.

One way of learning more about learned helplessness is to utilize a case study approach to determine the specific nature of the condition. Such an approach often employs observation data, interviewing techniques, and analysis of secondary data sources. Using a case study format, information about a student's family background, teacher and peer relationships, and achievement orientation can be gathered.

The purpose of this study was therefore twofold. The first purpose was to develop a comprehensive profile of one extremely learned helpless sixth-grade student. This included gathering background information on the child, observing her various classes throughout the school day, and conducting personal interviews with the student and her teachers. The second purpose was to suggest an intervention program based on the data represented in the student's profile.

\section{Method}

This study focused upon a 13-year-old female student named LuAnn (a pseudonym) who attended a public middle school in North Carolina. The lead author, a part-time physical education teacher at the school, had observed this student's lack of motivation, tendency toward expecting failure outcomes, and hesitancy in accepting responsibility, and thus, had identified the youngster as a possible victim of the "leamed helplessness" syndrome. Other teachers and administrators at the school had noticed the same symptoms, but were unfamiliar with the learned helpless condition. In cooperation with the school administration, a profile of the child was created that included family background information, comprehensive schooling information, and input from LuAnn's previous elementary 
teachers. The profile was consistent with the suggestion that LuAnn was "learned helpless." Because we were interested in obtaining a more objective measure of the child's locus of control, the Intellectual Achievement Responsibility Questionnaire (IAR; Crandall, Katkovsky, \& Crandall, 1965) was employed in the study.

The IAR was designed to assess children's perceptions of their personal control over success and failure experiences. The scale consists of 34 questions, half of which measure children's attributions for success, and half of which measure their attributions for failure. Each question pertains to a success or failure experience that occurs routinely in the life of children. The children may choose between two answers, one that attributes the success or failure to themselves and the other that attributes the success or failure to a significant person in their immediate surroundings. Knowing children's attribution orientations has been helpful in identifying youngsters who fall within the boundaries of "learned helplessness." The IAR results suggest that when children consider themselves to have little control over their positive and negative achievement experiences, they have virtually no reason to change their behavior since it seemingly would not result in outcome differences. Numerous studies on "learned helpless" children have used the IAR to measure internal and external attribution patterns (Martinek \& Griffith, 1994a; Dweck, 1975; Shelton, Anastopoulous, \& Linden, 1985).

Validity of the IAR has been previously established by correlating internality (IAR) with children's time spent on intellectual tasks and their levels of intensity in approaching learning activities (Crandall et al., 1965). Correlations of .70 and .60, respectively, were reported for both sets of measures. In addition, IAR scores were found to correlate well with school grades for both elementary and high school samples (Crandall et al., 1965).

In the present study, LuAnn completed the IAR, resulting in a score 2.5 standard deviations below the mean for sixth-grade girls. This result indicated that LuAnn felt little control over various achievement outcomes. It provided another piece of evidence to reflect LuAnn's tendency towards learned helplessness.

The lead author, a part-time teacher at the school, had kept notes regarding LuAnn's behavior in physical education class and during the lunch period throughout the school year because she was able to observe LuAnn on a daily basis in these two settings. In addition, we deemed it important to observe LuAnn's behavior in a broader context. Therefore, LuAnn was also observed 2 days a week for 2 weeks in other academic settings, including math class and science class. The observer (the first author) was as discreet as possible in attending the classes; the teachers were informed of the observer's intentions while observing, although the students in the classroom (including LuAnn) did not know the purpose of the observer's presence.

The observer took notes on LuAnn's behavior during the time period and at the end of the day recorded the observed events on a word processor. In addition, once or twice a week the observer interviewed LuAnn and the individual teachers who were involved in the observation periods. With permission of the student and teachers, the interviews were tape-recorded and later transcribed. The interviews were beneficial in gaining a more expansive perspective on LuAnn's behavior. The observations and the interview data further completed LuAnn's profile.

\section{Analysis of the Data}

The data were analyzed qualitatively. By using a constant comparison technique, themes that were frequently stated and restated in the data were selected. These themes were recurring threads of the events that best described LuAnn's learned helpless condition. The data were reorganized to fall under these specific themes. The following is a qualitative 
analysis of the information gleaned from LuAnn's background information and from the observation and the interview data collected. Three themes relating to LuAnn emerged from the data: (a) her family relationships and circumstances, (b) her relationships with teachers, and (c) her relationships with peers.

\section{Family Relationship and Circumstances}

LuAnn lives with her mother, father, and brother. The home situation appears to be stable at this time, although it has not always been.

Mother. LuAnn's mother is 35 years old and works for a uniform company. She married at age 15, and dropped out of school while in the fifth grade. She described herself to a school psychologist as being immature and having low self-esteem. She grew up in a divorced home, and feels that she and her husband's periodic separations over the years have hurt LuAnn. Discipline has been a source of disagreement between the two: The husband believes his wife is too strict with the children. They spanked LuAnn as a young child only as a method to correct bedwetting. The mother believed that LuAnn's bedwetting was intentional and done solely for attention. It is not known whether bedwetting continues to be a problem for LuAnn, but she does still have problems staying dry at school.

Although there is no indication of abuse at home, there are signs of neglect. LuAnn frequently wears dirty clothes to school: Her clothes reek of a urine odor; her socks are black with dirt; and her tennis shoes are worn even after the material is rotten. Several times during the year LuAnn came to school wearing no underwear because none was clean at home. Most recently, LuAnn came to school on 2 consecutive days wearing no underwear. She said that her mother was at the beach, and there were no clean clothes in the house. LuAnn typically arrives at school with dirty, wrinkled clothes, as well as unkempt hair and an unwashed face. Much of LuAnn's clothing is inappropriate for her age. She is usually dressed in attire that would be appropriate for a younger child.

LuAnn's untidy appearance at school is not the only significant factor; her lack of preparation for classes is also apparent. She does not bring pencils, papers, notebooks, or homework to class as directed. She is constantly going to class without the necessary materials. LuAnn's math teacher said that the mother agreed to cooperate in helping LuAnn prepare for classes, although the mother's good intentions faded quickly. She does not check to make sure LuAnn does her homework or has her school supplies ready.

Another area effecting LuAnn's school work may be a lack of good eating habits. LuAnn's physical education teachers report that she often complains of feeling sick after gym class, and they think that much of the problem may be the result of skipping breakfast. LuAnn rarely eats anything for breakfast and could very well feel weak after running around for a half hour on an empty stomach.

Although the mother's lack of education may in some ways explain her inability to offer more direction to her daughter in functioning in the school setting, a lack of finances in the home may offer another explanation for some of LuAnn's neglect. LuAnn has very poor vision, particularly in her left eye, but had not worn glasses during the school year until April. She says she cannot do addition problems with long rows of numbers because the numbers blur, and she cannot keep them straight. She expressed a strong desire to get glasses and said that her mother told her they would take her to get fitted for some as soon as they could. Recently, LuAnn was fitted for glasses, although the frames that were chosen were appropriate for adults instead of children. The frames appeared to be several sizes too large for LuAnn's face. She wore them for 2 days, but on the 3rd day she came to school without them, and said that they had been broken and were being fixed. The vision problems are not new to LuAnn. Her school records from the first grade note that her poor score on the Wechsler IQ test may have been due more to bad eyesight than to 
a lack of intellectual ability. LuAnn scored above $4 \%$ of the population of first graders on the measure.

Besides glasses, LuAnn's dress may reflect the family's struggling financial situation. LuAnn was elated to finally get a new pair of tennis shoes; she kept looking down to admire them during school for the first few days when they were brand new.

Although it appears that in many respects LuAnn is neglected at home, she and her mother do seem to have a positive relationship. Her mother frequently surprises LuAnn with little gifts such as a T-shirt or hat from the beach, a purse from the mall, or a new pair of shorts. LuAnn loves receiving these presents and always points out her new things to her teachers the next day at school. On LuAnn's 13th birthday in January, her mother made the occasion a special one by having a nice dinner, a birthday cake, and presents. LuAnn commented one day that her mother felt a little jealous when LuAnn spent a lot of time with her aunt, because "when I'm over at my aunt's house, my mama feels like my aunt is my mama and she's not."

Also, to her credit, LuAnn's mother has always cooperated with the school district in trying to provide the kind of specialized attention that LuAnn has needed in school. Her mother has never denied LuAnn the opportunity to be tested, or to receive special treatment in speech, language, or physical therapy. Her mother is willing to meet with LuAnn's teachers upon request and usually agrees to help monitor her daughter's study habits, even though the follow-through is often limited.

Father. LuAnn's home situation may have improved in recent months. Her father is living with the family again, and things at home seem to be good. LuAnn's father is 37 years old and works for a trucking company. Lately, he drops LuAnn off at school when she does not ride the bus. One morning he offered LuAnn a cup of coffee and she eagerly accepted. She spilled the cup of coffee all over her clothes but wore them to school anyway; there were big damp stains on her jeans and light blue sweater. She said that her father told her to change clothes, but she told him that she did not want to because she was wearing her favorite clothes. He didn't force her to change. LuAnn also reported that her father helped her with various class projects.

Brother. LuAnn's brother is seventeen years old and attends a high school in the district. He works at a fast food restaurant part-time, but seems to spend time with his sister. In fact, it appears that he has the most positive influence on LuAnn's life. She adores her brother, and talks about him frequently and affectionately. Once she brought a picture of him to school and carried it around with her all day, showing it to her teachers and some students. During her classes she held the picture in her hand and occasionally stared down at it.

The brother is protective of LuAnn; in the fall he arrived home to find a boy about to beat up LuAnn on their front lawn. The brother sent the boy away with a warning that he had better not ever bother LuAnn again. When LuAnn tells him of incidences at school where she has been told by students that she is stupid, he assures her that she is not.

Not only has the brother been good to LuAnn, but his friends have been very nice to her, as well. The brother's best friend often eats dinner with the family and will play with LuAnn when he's at the house. LuAnn admits to having a crush on him and comments that he plays rougher than her brother, but it is OK because she likes it. The friend helped LuAnn with her big science project. Also, one night the brother and his friend showed up at LuAnn's aunt's house and tried to scare the family members who were there, including LuAnn. LuAnn loved it, and remembers the incident frequently.

The brother has a girlfriend who has also treated LuAnn very well. The girlfriend always takes time to talk, and on LuAnn's birthday she came to the party and brought LuAnn a gift of a light blue sweater and a matching pair of socks. LuAnn was thrilled with the attention and the gifts. 


\section{Teacher Relationships}

LuAnn has experienced frequent problems throughout her public schooling thus far, although the records indicate that she has always been a pleasant, friendly child to have in class and has had excellent attendance over the years. In the first grade, her teacher described her as having a very short memory span, having poor gross motor development and control, being easily confused, being fearful of trying to do things, needing excessive amounts of teacher help, and being dependent upon others. LuAnn would wait for people to do things for her.

In the second grade, the hygiene problems became more evident. LuAnn had frequent accidents in school, and her clothes smelled of urine. She began receiving adapted physical education and occupational therapy. LuAnn's third-grade teacher described LuAnn as very considerate, sympathetic, caring, totally unaggressive, and easily distracted. Her academic skills for the year were on a first-grade level, and her score on the Wechsler IQ test was extremely low. At this time her "learning disabled" identification was changed to "educably mentally handicapped."

In the fourth grade LuAnn had only been absent one time by January. She was in a self-contained class and was described as having "extreme difficulty in establishing and maintaining good relationships. Lacks age appropriate social skills. At times, withdraws. Low self-esteem." She was close to age level on visual-perceptual skills and motor accuracy. Her strengths were her friendliness and appreciation of praise.

Presently, LuAnn is in the sixth grade and exhibits third-grade reading, spelling, and math skills. She has been recommended for a self-contained setting, but is not in one at the time because of a lack of school resources.

What follow are profiles of the math, science, and physical education teachers who are working with LuAnn in the sixth grade.

Math Teacher. LuAnn has only seven other students in her math class, so the teacher, Ms. Struthers (a pseudonym) is able to give her considerable attention and direction. Each of the students in the class works at a different pace, so LuAnn is able to move along at the rate most conducive to her learning. Ms. Struthers constantly moves around the class and frequently stops at LuAnn's desk to check her work. Most recently, LuAnn finished her unit on addition and was working on subtraction skills. When the teacher has her count from 20 backwards, LuAnn sometimes has to pause at 11 and 12 because she gets confused on the numbers. She has to use her fingers to subtract even such problems as 5-4. Ms. Struthers feels that many of LuAnn's problems are tied to her poor concentration skills. Ms. Struthers said LuAnn has a pattern of getting three problems right, one wrong, another three right, and then three wrong. The teacher believes LuAnn is working and has a total lapse of concentration.

Ms. Struthers is very positive with LuAnn, and her patience seemingly never runs dry, although the teacher does admit that LuAnn's case is frustrating. LuAnn does not bring materials to class, does not do homework, and frequently takes advantage of a bathroom pass by staying out of class too long.

Another frustration of the teacher is the ongoing task of keeping other students from making fun of LuAnn. Ms. Struthers has found that a strong reprimand is practically the only effective method to deter the students' harsh teasing. She constantly praises LuAnn for her effort and is quick to tell her that she is smart and capable. Ms. Struthers has found that standing right by LuAnn is a sure way of getting a positive response. She says, "LuAnn loves individual attention, but she does not respond to material rewards."

Ms. Struthers has spent excessive time working with LuAnn this year and seems to be devoted to the student's best interest. She feels that LuAnn is making social and academic progress, though at an extremely slow process. 
Science Teacher. LuAnn goes from her first period math class with 7 other students to her second period science class with 30 students. Ms. Jones (a pseudonym), the science teacher, says it is difficult to cater to LuAnn's special needs with a classroom full of students. LuAnn never brings her notebook, homework, paper, or pencil to class and, thus, rarely participates. For the most part, LuAnn sits and listens and watches. Often she puts her head down on her desk and withdraws from the activity of the class. On the days when the observer was in class, LuAnn seemed to participate more, but Ms. Jones noted that LuAnn's participation on those days was not typical. More often, LuAnn does not take notes, work on assignments, do homework, or follow the teacher's instructions. LuAnn says that part of the reason that she does not complete the work is because when she asks Ms. Jones for paper, the teacher will not give her any, and just tells her to borrow from someone else in the class. When reminded that teachers cannot afford to supply all their students with paper, LuAnn responded, "But see, I'm half LD, and I'm stupid. . . . I'm stupid and all that." The interviewer told LuAnn that she was not stupid, and LuAnn quickly agreed. LuAnn said, "I know it. . . . Even my brother tells me that I ain't stupid."

The students were assigned a big science project that was to account for $25 \%$ of their grade for the 9-week period, and LuAnn initially turned in a very weak project. The project had to be three dimensional, and LuAnn turned in a picture drawn on a piece of cardboard. Ms. Jones scheduled a conference with LuAnn's mother to explain the requirements for the project and then extended the due date so that LuAnn could have another chance to work on the assignment. The mother indicated to Ms. Jones that the family would help LuAnn complete the project. They did, and LuAnn's grade was greatly improved. However, LuAnn was extremely disappointed when Ms. Jones first told her that her project had received an F. LuAnn said, "She [Ms. Jones] said it was good, but a 60 ain't good." LuAnn took the project home, worked on it more, and brought back a much improved project.

LuAnn likes Ms. Jones and said one day that she wished the teacher was at her table in the cafeteria at lunch time, because Ms. Jones would not mind if LuAnn sat at her table. Ms. Jones described LuAnn as friendly, pleasant, and very receptive to praise and attention. LuAnn even reminded the teacher of her approaching birthday 4 days before it came.

Physical Education Teachers. LuAnn has three physical education teachers, two women and one man, that work with her group. She likes the class and participates for the most part, except on occasion when she does not want to perform in front of the class because she is afraid her peers will laugh at her.

One of the female teachers feels that LuAnn's biggest problem is that she wants attention. LuAnn is capable of opening her locker, taking a shower, getting dressed on time, and participating fully in the class each day. When LuAnn has problems in one of these areas, the teacher feels that it is due to LuAnn's desire to receive more attention, and not to an inability on the child's part.

The male teacher is friendly to LuAnn, although he does not help her individually with skills, and he does not arrange the class in a way that would promote the maximum practice time for the students. The situation is unfortunate because LuAnn could benefit greatly from a class structure that optimized students' participation.

\section{Peer Relationships}

A significant problem in LuAnn's life is her poor social skills. She has no friends at school and does not know how to begin to make a friend. Students do not want to be around her for numerous reasons, the main reason being her appearance and poor hygiene. Often her clothes smell of urine, and in the sixth grade, she still has problems staying dry at school. LuAnn says that she can control when she goes to the bathroom, but that 
sometimes she does not feel like going to the trouble of waiting until she gets to the restroom. Her mother has told the school nurse that LuAnn has seen a doctor numerous times, and there is no physical reason to account for the wetting problem. The teachers feel that the situation prevents LuAnn from making social progress with other students. LuAnn does not acknowledge the importance of staying dry. She feels that the insults about her odor are meant only to be mean, but that they have no factual base. She says she does not smell, her clothes are clean, and she comes to school fresh each day.

Math Class. LuAnn probably has the fewest problems at school in her math class, since the class is so small. Adolph (a pseudonym) tells her to move her desk farther away from his, and insults her in numerous other ways, but usually Ms. Struthers is within hearing distance and can stop the teasing quickly. Jack (a pseudonym), another student who rarely misses an opportunity to make fun of LuAnn, was in the class for a while but was moved into another math class. LuAnn was pleased about that because she felt that when Jack was cruel to her, Ms. Struthers would laugh along with the students. LuAnn says the teacher does not laugh when Adolph picks on her, just when Jack does. LuAnn believes it is not fair that people laugh at her because she is "half handicapped." She says, "Cause I can't hardly write that good, and I'm slow." She says that Adolph has relayed that information to her. One day Adolph was absent and Ms. Struthers wanted LuAnn to sit in his chair so the students would be closer together, but LuAnn was hesitant to sit there because she wasn't sure how Adolph would react if he knew about it. The teacher told LuAnn that it did not matter what Adolph thought about it because he was absent, and no one cared whether he would like it or not like it. LuAnn sat in Adolph's chair for the day.

LuAnn occasionally has a normal conversation with another student. One snowy day she and a student were the first to arrive at class and they discussed with one another their displeasure in hearing that the 2-hour weather delay meant that they would not have physical education class. They were both disgusted and wished that they could change the schedule. Though LuAnn rarely engages in such dialogue with her peers, she is pleased when she observes that another student has done well. For example, she smiles brightly when a student successfully calls out the multiplication pattern for a number.

Science Class. The large number of students in the science class makes it difficult for Ms. Jones to monitor the youngsters' comments to LuAnn. Most of the problems in the science class are minor ones that add up over time. For example, when Jack passes out papers to the class, he does not give one to LuAnn. Billy (a pseudonym), the boy who sits next to LuAnn, one day blurted out in the middle of the teacher's lecture, "Would you tell her to stop looking at me?' Ms. Jones told the student not to worry about it, so the student looked straight at LuAnn and said, "Stop looking at me." The teacher said, "It would be nice to have someone look at you occasionally." The class laughed, and Ms. Jones continued with her lesson. Earlier in the class another student had called Billy a "stupid taco shell" in front of the class, so Billy may have been attempting to take out his revenge on LuAnn.

One day the class had a different teacher, and the students were allowed to sit anywhere. LuAnn chose a desk that faced the side wall. She said she chose the desk hoping that Jack would not make fun of her if she sat away from him where they would not be looking at each other. LuAnn said,

I just wonder if it didn't work. . . . Well, all right, when I walked in I went in there and sat down away from everybody else. When I walked in, I went down there and sat down . . . and it worked. Jack didn't say a word to me.

She said the situation may have been helped because one of the teachers had been telling 
Jack to stop making fun of her. During the same class period LuAnn went to her locker to get her folder, and when she returned to the classroom one student made a loud "ehhhhhhh" sound, and another student loudly coughed six times like he was going to be sick.

Physical Education Class. In general, physical education class is the most positive part of the day for LuAnn, mainly because there are three teachers for the group, and she receives a good deal of personal attention. The students in the class never want LuAnn to be in their group, and no one ever chooses LuAnn to be his or her partner for an activity. When the teacher appoints LuAnn to a group, the students in the group usually roll their eyes in unison. When LuAnn does not do well with a skill or activity, the students are quick to yell at her. Even though LuAnn has improved in every aspect of the physical education class this year, she perceives that she is not very good, because students are constantly telling her that she is terrible.

Actually, LuAnn is about average in her ability in physical education class, although she is so unsure of herself and has so little confidence, that she is afraid to be aggressive in a game and to try very hard. One day the class was having relays, and LuAnn was afraid to try a difficult skill that she had previously never attempted. She knew that the entire class would laugh at her if she made a mistake. The teacher did not force her to run in the relay, but did have LuAnn practice the skill at the end of the period when the rest of the class was in the dressing room. Because of this lack of confidence, students avoid including her in the activity whenever possible. Occasionally, the teachers quietly instruct a student to throw the ball to LuAnn.

One day when the students were in line practicing serving a volleyball, LuAnn told the teacher that Adolph kept telling her to get out of his way. He did not want her in the serving line with him. The teacher told LuAnn to get back in line and simply tell Adolph to get out of the way if he said anything else. He did not. A few minutes later LuAnn came crying to the teacher saying that she had been kicked, but she did not know who did it. She had a black mark on her skin.

One other major incident happened recently. The sixth grade had not dressed out because the seventh-grade girls had been practicing a dance and were to perform it during the period for the entire school. The lights were turned out in the gym for the dance, and when they were turned on again, one student was yelling at the teacher to go to LuAnn because she was screaming. While the lights were out, two or three boys had kicked LuAnn hard in the back and the side. LuAnn was crying, nearly hysterically, but claimed that she did not know who did it. The teacher felt that she knew who struck LuAnn, although the students denied having any involvement, and no one in the class could or would offer any information.

Although this incident involving physical abuse towards LuAnn is the exception, there is very little positive exchange between LuAnn and the class. One girl, Beth (a pseudonym), is always very kind to LuAnn, although her kindness appears to come from sympathy, rather than a desire to be a good friend with LuAnn. The majority of the other positive experiences that occur in LuAnn's life at school involve exchanges between her and her teachers.

Lunch. Each day LuAnn sits alone at lunch. She says she would prefer to sit with other students, but each time she sits down by people, they slide several chairs away from her. She said that when she has attempted to sit by a teacher, the teacher tells her that other students have already reserved the places. LuAnn eats her lunch, and then sits quietly and stares off into space until the lunch period is over, and it is time to leave the cafeteria. One day during lunch LuAnn told a teacher that she did not feel good, and Jack overheard her and told the teacher that LuAnn "says that all the time." He said that LuAnn never 
felt good. LuAnn was angry about his comment, and told him that she did not always say that. She was close to tears.

\section{Discussion}

The overall profile of LuAnn that resulted from the data sources (i.e., observations, interviews, and school records) clearly reflected a learned helpless pattern of responses. To begin, LuAnn was inclined to believe that intellectual and social prowess is a fixed trait and that there was little she could do to change her situation. Numerous examples may be noted, but the following two quotations best reflect this orientation. The first concerns a student who made fun of LuAnn in math class. LuAnn said, "And I don't think it's funny when he says something about me. And everybody in the class is laughing about me. And, well, I'm half handicapped ... 'cause I, 'cause I can't hardly write that good, and I'm slow." She went on to say that a student had told her that she was slow. A second response was given when the researcher asked LuAnn why she did not get her materials out sooner in math class. LuAnn replied, "But see, I'm half LD and I'm stupid. ... I'm stupid and all that. And everybody thinks I'm stupid!" A few minutes later she said, "But I ain't stupid, I just work too slow."

These examples reflect LuAnn's low ability perceptions and a sense of uncontrollability over outcomes. They also corroborate findings reported by Martinek and Griffith (1994a) who found that learned helpless students typically attribute failure to ability rather than to external factors such as the difficulty of the task or the disposition of the teacher.

The results also show that LuAnn is accustomed to evaluating her performances in relation to the assessments of others. For example, LuAnn detects that her science teacher is attempting to give her a positive judgment, even though the actual grade on the project reflects the more accurate appraisal. She was very disturbed about the evaluation she received on her project. She explained, "Ms. Jones told me it was good, but a 60 ain't good."

In her social relationships with peers, LuAnn perceived virtually nothing positive regarding her capabilities for interacting with others. The situation is best described in her own words:

I was in Ms. Oliver's [a pseudonym] class just sittin' there and Bob [a pseudonym], he just started picking on me, and everybody in the class started telling me that I stink. I tried to tell them to shut up, but they don't listen to me. They'd just sit there, and they just kept laughing at me and all that. And when I started crying, Ms. Oliver came up to me and asked me what was the matter. I told her that the whole class was picking on me. She told the whole class not to pick on me no more. And that helped, 'cause, well, she told them, and they stopped picking on me, and then they started picking on me again.

This resulted in Ms. Oliver making the entire class, including LuAnn, write a paragraph about how to behave, in class. LuAnn said, "And I didn't do anything. They was just picking on me, and Ms. Oliver made me do it, too. I wasn't doing nothing."

According to Elliot and Dweck (1988), LuAnn could survive with her belief that intelligence and performance is fixed if she had high confidence in her present ability. Unfortunately, this is not the case. Depicted below are LuAnn's statements about her various classes:

1. Describing herself in her science class she said, "I'm slow."

2. Conceming long addition problems in math class LuAnn said, "I can't do those too good." 
3. In physical education class LuAnn admitted, "I can't throw too good."

4. During lunch LuAnn explained, "I sit down at a table, and everyone moves away from me."

This lack of confidence in all areas of LuAnn's experience, coupled with her intelligence theory and her performance goals leads to a particular behavior pattern that is characterized by an avoidance of challenging tasks and a tendency to have low persistence for activities. LuAnn does indeed avoid challenges and has low persistence in each of her classes:

1. In science class, the child typically chooses not to participate with the class.

2. In math class, LuAnn raises her hand for the teacher when she cannot immediately work a problem. She displays little persistence to master a task alone.

3. In physical education, LuAnn waits to engage in a task until there is prompting from the teacher to begin.

4. During lunch she has resigned herself to sitting alone.

The main purpose of this study on LuAnn was to analyze her situation; this analysis allowed us to have a better understanding of learned helpless behavior. Of particular significance was the pervasiveness of LuAnn's learned helpless condition. It appeared LuAnn's feelings of uncontrollability extended beyond the context of a single school setting or circumstance. Avoidance of academic and physical tasks was evident in the classroom and gymnasium and was an apparent outgrowth of a learned helpless condition. LuAnn's profile is interesting in light of Seligman's (1990) notion that learned helplessness can exist in varying degrees of severity. The extent of that severity can have a profound effect on recovery from failure and responsiveness to intervention.

A second purpose of the study was to design an intervention for LuAnn. However, because of the nature and severity of LuAnn's learned helpless condition, designing an intervention for her was a more complex undertaking than originally anticipated. We had hoped to develop a rather broad intervention that would help alleviate LuAnn's learned helpless behavior across contexts (e.g., the physical and academic domains), but after analyzing the data, it appeared that a narrow focus was needed in intervening. A more effective strategy would involve targeting one particular setting where LuAnn displays maladaptive motivational patterns (e.g., physical education class).

Perhaps the best approach to an intervention in physical education would involve after-school sessions that devote time to practicing skills to be used in upcoming lessons. For example, if LuAnn's teachers knew what they would be teaching in 2 weeks, perhaps LuAnn could begin to practice those skills for the upcoming activities. This would give her the opportunity to familiarize herself with the equipment and the setting, and by the time her class was on the unit, she would have already demonstrated some success at the activity. These sessions could involve a variety of positive self-talk activities, attribution retraining, goal-setting, and modeling to help LuAnn focus on learning goals, rather than performance goals. While this intervention proposal would require additional time from the teachers or other adults to conduct such a session, the time would seems well spent when the detrimental effects of learned helplessness are considered. Possibly a small group of learned helpless children could work together in these after-school sessions. Although LuAnn's learned helpless condition may reach across the broad spectrum of her school environment, other children may suffer from helplessness in only one subject (e.g., physical education). 
Although this study was unable to propose a complete intervention for learned helplessness in physical education, implications for teachers working with learned helpless students did surface. It should be noted that the suggestions presented here are not new to teacher education programs, but they appear to be so vital to the success of learned helpless students that they may be worth stressing, repeating, and reviewing:

1. Stress effort and improvement over outcome. As mentioned earlier, learned helpless children are not perceptive at recognizing their improvement, perhaps because they focus more on comparing their performance to other students' abilities. Thus, individual improvement is an often-overlooked factor. For example, one day LuAnn said, "I can't do sit-ups too good." In truth, at the beginning of the school year she could not do even one sit-up, but by February she was doing 25 sit-ups. However, because many of her classmates could do $\mathbf{4 0}$ sit-ups, she felt that her performance was still poor. When it was pointed out to her the great strides of improvement she had made through the last several months, she agreed and left the class flashing a big smile.

2. Structure the learning environment for maximum participation. Although many physical educators do this naturally, classes can still be observed where one student is active while the rest of the class serves as an audience. Learned helpless children frequently expect failure outcomes, and the stress put upon a child who is forced to perform in front of a group of peers can be detrimental. For example, one day LuAnn was close to tears because she did not want to engage in a relay race where she was to run swinging and jumping through a rope the distance to a cone. She had never practiced the skill before and was sure that she could not do it. She anticipated her classmates laughing at her when she made a mistake. When the class is structured so that each student can practice in her or his space, the threat of peer ridicule is minimized and the potential for positive growth and participation is maximized.

3. Encourage students to engage in physical activity outside of school. Learned helpless children perceive themselves to have low ability, so they logically avoid seeking situations where they are forced to perform. Students might be prompted to practice a skill at home if their physical education. teachers suggested a particular task, such as jumping rope or dribbling a basketball. Perhaps a conversation with students' parents could create additional support for children's increased participation in physical activity.

4. Create leadership and responsibility roles for the students. Learned helpless children do not perceive that they have control over the outcomes in their lives, so they can benefit from being in situations that promote feelings of responsibility. Involving children in tasks of helping with equipment, demonstrating an activity, or running errands. can help them experience feelings of control and responsibility. Teachers should look for ways to include students in every phase of the class. Learned helpless children are sometimes slow and hesitant, and they can be easily overlooked. Teachers may naturally employ other students to assist who are more aggressive, efficient, and enthusiastic.

\section{Conclusion}

This study was a first attempt to provide an in-depth examination of a learned helpless student in the physical and academic domains. Future research should continue to explore the impact that teachers can have in structuring the learning environment in a way that maximizes opportunities for all students to experience heightened perceptions 
of control and competence in their physical education class, as well as throughout the school day.

\section{References}

Crandall, V.C., Katkovsky, W., \& Crandall, V.J., (1965). Children's beliefs in their own control of reinforcement in intellectual achievement situations. Child Development, 36, 91-109.

Dweck, C. (1975). The role of expectations and attributions in the alleviation of learned helplessness. Journal of Personality and Social Psychology, 31, 674-685.

Dweck, C.S. (1986). Motivational processes affecting learning. American Psychologist, 41, 1040-1048.

Dweck, C.S, \& Goetz, T.E. (1978). Attribution and learned helplessness. In J.H. Harvey, W. Ickes, \& R.F. Kidd (Eds.), New directions in attribution research. (Vol. 2, pp. 157-179) Hillsdale, NJ: Erlbaum.

Elliot, E.S., \& Dweck, C.S. (1988). Goals: An approach to motivation and achievement. Journal of Personality and Social Psychology, 554, 5-12.

Fincham, F.D., Hokoda, A., \& Sanders, R. (1989). Learned helplessness, test anxiety and academic achievement: A longitudinal analysis. Child Development, 60, 138-145.

Kozol, J. (1991). Savage inequalities. New York: Crown.

Martinek, T., \& Griffith, J.B. (1993). Working with the leamed helpless child. Journal of Physical Education, Recreation and Dance, 64(6), 17-20.

Martinek, T., \& Griffith, H.B. (1994a). Learned helplessness in physical education: A developmental study of causal attributions and task persistence. Journal of Teaching in Physical Education, 13, 108-122.

Martinek, T., \& Griffith, H. B. (1994b). Pervasive learned helplessness: An examination of children who can but won't. Paper presented at the AIESEP World Congress, Berlin, Germany.

Meyer, N.E., \& Dicht, D.G. (1981). Effects of reward-schedule parameters and attribution retraining on children's attributions and reading persistence. Bulletin of the Psychonomic Society, 24(1), 65-68.

Miserandino, M., \& Hoffman, J.P. (1990). Attributional retraining as a method of improving athletic performance. Paper presented at the Annual Meeting of the American Psychological Association, Boston.

Nicholls, J. (1984). Achievement motivation: Conceptions of ability, subjective experience, task choice, and performance. Psychological Review, 91, 328-346.

Prapavessis, H., \& Carron, A.V. (1988). Leamed helplessness in sport. The Sport Psychologist, 2, 189-201.

Reynolds, W., \& Miller, K. (1989). Assessment of adolescents' learned helplessness in achievement situations. Journal of Personality Assessment, 53, $211-228$.

Seligman, M.E.P. (1990). Learned optimism. New York: Pocket Books.

Seligman, M.E.P., \& Maier, S.F. (1967). Failure to escape traumatic shock. Journal of Experimental Psychology, 74, 1-9.

Shelton, T., Anastopoulous, A., \& Linden, J. (1985). An attributional training program with LD children. Journal of Learning Disabilities, 18, 261-265.

Stipek, D.J. (1993). Motivation to learn: From theory to practice. Boston: Allyn \& Bacon.

Stipek, D., \& Gralinski, H. (1991). Gender differences in children's achievement-related beliefs and emotional responses to success and failure in math. Journal of Educational Psychology, 83, 361-371.

Thomas, A. (1989). Ability and achievement expectations: Implications of research for classroom practice. Childhood Education, 65, 235-241. 
Copyright of Journal of Teaching in Physical Education is the property of Human Kinetics Publishers. Inc. and its content may not be copied or emailed to multiple sites or posted to a listserv without the copyright holder's express written permission. However, users may print, download, or email articles for individual use. 